\title{
Hubble upgrade review stirs concern over impact of NASA budget cuts
}

Washington. The US National Aeronautics and Space Administration (NASA) is considering whether to scale back its plans to maintain and upgrade the Hubble space telescope, only months after a successful repair trip rescued the project and gave the agency its biggest public relations boost for several years.

Wesley Huntress, NASA's associate administrator for science, has told scientists at the agency and outside astronomers to postpone proposals for an advanced camera for Hubble - due to be fitted on the platform during a 1999 maintenance flight - pending a review covering the Shuttle missions planned to Hubble in 1997, 1999 and 2002.

The postponement comes only three weeks after NASA had issued its first 'announcement of opportunity' for the advanced camera. It has angered scientists, and has led to speculation that budget pressures on the agency may lead it to sandwich the first two trips into one mission in 1999 , when a Shuttle mission will be essential to raise Hubble's orbit and prevent it falling to Earth.

Such a course of action would mean a two-year stretch out of the construction of two new instruments, the Near Infrared Camera Multiple Object Spectrometer (NICMOS) and the Space Telescope Imaging
Spectrograph(STIS), both due to be launched and fitted in 1997. It might also lead to a decision to shelve the proposed advanced camera, which scientists say is needed to exploit fully the newly improved resolution being achieved by Hubble. It would, however, save NASA the costs of the shuttle launch in 1997.

\section{IMAGE UNAVAILABLE FOR COPYRIGHT REASONS}

\section{Will impact of last December's repair mission (simulated here) be kept up?}

Ed Weiler, the programme scientist for Hubble, is seeking to reassure scientists that the review in itself does not mean that the programme will be radically changed. "I cannot predict the outcome of the review," he says. "I don't think anyone should take the postponement too much to heart."

\section{Ocean experiment is put on hold}

San Francisco. The Advanced Research Projects Agency of the US Department of Defense has decided to hold back funding for part of an experiment to measure global warming in the ocean, pending a hearing being held in response to claims from environmentalists that the experiment could be harmful to whales and other wildlife.

The study is known as Acoustic Thermometry of Ocean Climate, and has been designed by the Scripps Oceanographic Institute. It is planned to measure changes in ocean temperature by sending sound waves from transducers deep in the water near Monterey Bay, California, and in Kauai, Hawaii.

The experiment became embroiled in controversy last month when a group of marine biologists claimed that the sound waves - coded signals of up to 195 decibels to be transmitted at between 60 and $90 \mathrm{~Hz}$ for 20 minutes every four hours would disrupt the habitat of whales, potentially damaging their health and perhaps even causing their death (see
Nature 368, 485; 1994).

The halt affects only the California part of the experiment. But Scripps cannot continue until work at both sites is approved. Many prominent experts in marine mammal biology and bioacoustics have come to Scripps' defence, arguing been grossly exaggerated.

Most of the criticism has come from Hal Whitehead and his wife, Lindy Weilgart of Dalhousie University, both experts in sperm whales. Whitehead and Weilgart argue that the noise transmissions could seriously disrupt the habitat in which the whales live; their critics claim that they have become "too close to

Kenneth Norris of the University of California at Santa Cruz, a leading cetacean biologist, has described the experiment as "a brilliant solution to a vexing problem". But Andrew Forbes, deputy director of Scripps, says the delay will provide a useful opportunity to "educate the public".

Joel Shurkin that the claims of potential harm have their animals".
But some astronomers predict that the process will in itself damage the scientific activities of the telescope. "Everyone is concerned, and its hard to stay focused on your work when there is this kind of turmoil," says Jim Crocker, head of advanced programmes as the Space Telescope Science Institute at Johns Hopkins University in Baltimore, Maryland, which manages the Hubble science programme for NASA. "We've been reviewed to death on this programme. At some point you have to set your course and proceed on it."

NICMOS and STIS were halved in scale in previous reviews, and will now cost about $\$ 70$ million each. The principal investigator of NICMOS, Rodger Thompson of the Steward Observatory at the University of Arizona, Tucson, says that scientists should not be too concerned. "NASA is facing a reduced budget and I'd expect them to evaluate each of their options carefully," he says. "At the moment we are not hesitating. You cannot let these things divert you from the matter in hand."

But uniquely among NASA missions, Hubble is supposed to be regularly maintained and updated over its planned 15-year life. Advocates of this approach are calling on scientists to defend a concept that, they say, enables the potential of the maintained craft to be fully exploited.

More than 60 per cent of Hubble's total budget - twice that of some other programmes - goes on science. Frank Cepollina of NASA's Goddard Space Flight Center at Greenbelt, Maryland, Hubble's servicing manager, says scientists should rally round the concept of not throwing away assets. "Economically it is what makes sense, and it is what our customers - the public understand."

But NASA is having to work out how to absorb impending budget cuts without killing any of its biggest programmes. John Pike of the Federation of American Scientists predicts that Congress may cut as much as $\$ 400$ million more from NASA's \$14-billion budget for next year, on top of the $\$ 250$-million cut already proposed by the administration.

"I don't think anyone [at NASA] has a clue where that is going to come from," says Pike. Big programmes, including the space station, the Cassini mission to Saturn and the aeronautics programme, have support from key lobby groups, says Pike; "what's left is $\$ 10$ million here and $\$ 20$ million there". In scurrying after cost savings at Hubble, Pike says, Huntress "is in no different position from anyone else".

Colin Macilwain 